\title{
Capítulo 5 \\ Mandala ontológico. Hacia una ontología latinoamericana desde la apuesta de Rodolfo Kusch
}

\section{Desde el silencio}

Antes que nada, antes de la nada, antes del ser: silencio.

Todo: silencio.

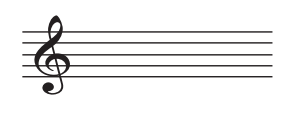

Originariamente, el silencio

es

y, desde su ser, deviene todo lo que es. 
Lo que es, en el principio, está

en silencio.

Esto no quiere decir que no haya

palabra

sino que ella está

en su más íntima intimidad,

nada más que

siendo.

Antes que nada,

la palabra es silencio.

Todo lo que es

aguarda

para develarse en su acontecer,

pero, ahí, está.

De lo contrario, el ser no sería.

Ser en silencio,

está.

Está el ser en su silencio,

originariamente.

Y, allí, se dice el ser

en su sentido

(sentido-ontológico),

no aún con estas palabras

con las que hoy día

también nos es posible

mentir.

Ser,

en esencia,

verdadea.

Silencio, ser y verdad

van a una.

Todo lo que es 
verdadea

en silencio.

El silencio originario

es la posibilidad de toda verdad,

o de la verdad toda

siendo.

Está la verdad en (el) ser,

está el ser en (el) silencio.

Silencio, verdad y ser

están.

Este estar ontológico

es la raíz desde la que se devela

todo lo siendo,

todo lo siente.

Lo-que-está-siendo.

Pero los seres humanos

nos hemos acostumbrado

a mirar,

a ver,

a observar

cosas,

objetos,

entes,

hasta el punto de creer

que la realidad

toda

es objetiva

y que en ella no hay más que ente.

De todas maneras,

cuando se abren los ojos

y se mira alrededor 
uno se topa con las cosas:

mero ente es lo que hay

ante la mirada objetiva

del ser humano.

Pero ¿solo nos basta la mirada?

La nuestra, pareciera ser,

no es más que una cultura de la mirada,

o, por lo menos, centrada

en el sentido de la visión.

Sin embargo, la sensibilidad

no se puede reducir al mirar

ni la razón debe guiarse solo

por la mirada

objetiva.

Cuando se está en silencio

se aprende a escuchar

también.

Y a saborear cada detalle,

a degustar el sabor

de lo que es,

tanto como a distinguir

vahos, aromas, esencias,

hedor;

y se aprende a tener tacto...

... a tener equilibrio,

a mover(se),

a intuir la chispa interna de las cosas,

a comprender la vida

(sentido vital),

y a estar-siendo-sentido

(sentido ontológico). 
Mirar no es suficiente:

ni es lo único ni es lo principal.

La historia nos ha llevado a entender que esta cultura centrada en la mirada (la de la razón objetiva) termina siendo monstruosa, seguramente como terminará siendo toda cultura centrada solo en uno de los sentidos.

Cuando se regresa al silencio original, cuando se está en el silencio, la comprensión de lo integro del ser nos conduce a no ser tan dogmáticos, nos lleva a cuestionar el mito de la razón universal (en cuanto razón objetiva), nos permite abrirnos a otros horizontes que enriquecen, justo, nuestro sentido de ser.

La razón de ser no es racional únicamente.

La comprensión del ser no se alcanzará solo dentro de los límites de la razón. Se nos impone, entonces, salir del dogma racionalista, objetivo, científico, ir más allá, romper estos límites, abrirse a otros horizontes, que posibiliten 
—quiérase o no-

sentido de ser,

sentido íntegro,

sentido ontológico.

Desde el silencio,

en el silencio,

más atrás de toda palabra,

más allá de todo nombrar

cosas, objetos, entes,

estamos

siendo

sentido.

¿Y cómo, entonces, recobrar ese sentido?

Volvamos, siempre,

—una y otra vez-

al silencio:

silencio

sileneio

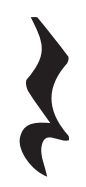

\section{El ser olvidado en el ente}

La palabra verdadera

siempre

verdadea. 
Pero la palabra que se aleja

de su silencio natural

tiende a falsearse.

Silencio y palabra van a una, porque ambas realidades

no son más que dos formas

de la misma realidad ontológica:

sentido.

Sentido, silencio y palabra

verdadean.

Aunque solo sentido,

o solo silencio,

o solo palabra,

tienden a perderse.

Verdadea la palabra

que, aún en silencio y siempre en silencio, devela su (fundamental) sentido:

sentido-de-ser,

sentido-íntegro,

sentido-ontológico.

Pero, a veces, nuestras palabras humanas

se quedan cortas,

no develan lo fundamental,

se opacan,

velan y hasta distorsionan

el ser de las cosas.

Por ejemplo, a veces, son demasiado

objetivas,

y la objetividad jamás será íntegra,

solo apaña lo óntico,

apenas logra quedarse con el ente, 
¡y hasta ha buscado darle al ente

el sentido del ser!

La realidad objetiva

puede alcanzar su máximo de cientificidad, pero no por ello

alcanza su máximo de verdad.

El conocimiento objetivo

puede ser muy racional,

pero no por ello

verdadea todo lo que debe verdadear.

Los conceptos

pueden responder muy bien a la lógica

que los sustenta,

pero no por ello

expresan la realidad íntegra

que - de todas maneras- jamás

alcanzarán a expresar.

Cuando se parte de conceptos

que pertenecen, ya de antemano,

a la realidad metafísica

de la que no podrán desligarse

y que, en ocasiones, no permitirán

la comprensión de un horizonte

más amplio y diverso,

por más que se hable de multiverso,

el referente no será otro

que el mismo universo

tradicional,

desde el cual se ha venido

suponiendo

todo lo que existe:

mundo real, objetivo y óntico. 
No es el ente.

Del ente solo podemos estar seguros

que tiene certeza,

y por ello se muestra

y nos ofrece su evidencia.

No es el ente,

siendo

en cuanto ser.

Lo mejor que podemos comprender

es que el ente es una forma de ser

de la que ciertamente no se duda

(y sobre cuya certeza

se han levantado muchos dogmas

objetivos y evidentes).

Por eso esta certeza ha encubierto

un problema

de fondo:

desinteresarse por el ser,

olvidarse del ser.

¿Y la pregunta por el ser?

Quedó indemne ya desde sus orígenes.

Fue doblegada por el ente.

Lo óntico se impuso sobre lo ontológico.

Se coartó el decir

-en su sentido ontológico-

y el ser quedó velado.

La lógica racional

no tuvo el cuidado sentiente,

y lo sentipensante

se desdeñó.

El paso del mito al logos

no fue más que otro mito 
que la racionalidad objetiva argumentó.

Pero el sentipensar

es natural

a toda inteligencia consciente,

a toda conciencia inteligente,

y tarde o temprano

se devela

en su naturaleza

ontológica.

La naturaleza verdadea lo que es.

O mejor dicho:

lo natural verdadea lo que es;

en efecto, y de manera más sencilla:

lo natural verdadea.

Y lo que verdadea siempre es el ser,

naturalmente

en silencio.

Y, tal vez,

justo por su silencio

lo olvidamos.

El ser no hace aspavientos bullangueros

sino que se mantiene en su estar silencioso.

Pero como está ahí entre todas las cosas, entre todos los entes,

nuestra mirada se fija en el ente,

se complace con las cosas,

y se deja llevar por ellas

sin detenerse en su alma.

Hay demasiado ruido.

Hay demasiada cosa.

Todo se nos ha vuelto ente. 
¡Y ya no creemos en el alma de las cosas!

Su ser nos quiere hablar,

pero le impedimos cualquier intento.

Hemos decidido observarlas,

analizarlas,

desbaratarlas,

hacerlas pedazos

hasta matarlas

destruyendo su esencia

para poder argumentar

que, en efecto, no hay esencia.

Con la sola mirada

hemos destruido el alma de las cosas.

¡Ya no son sino meros objetos!

Ahora:

todo ente es relativo

(y pareciera que de ahí se infiere

que el ser también lo es).

Pero, en el fondo, lo del ser ni importa

-hoy día一:

ese problema ya no es problema.

La actitud de los académicos

de nuestra época

es de total indiferencia

con el problema del ser.

Deviene entonces la sentencia

de aquel pensador:

¡el olvido del ser!,

Heidegger sentencia tajante:

¡la historia de la metafísica

no es más que la historia del olvido

del ser!

Y sin embargo,

la pregunta se mantiene. 
La pregunta por el ser acaece

de forma indubitable, con más veras ahora.

Ante la indiferencia

o la argumentación científica

de los académicos, se yergue

antes, ahora y siempre

lo que nos interesa

a todos los seres humanos:

ser.

Porque, es indudable, somos:

estamos siendo, no por nada.

Nos interesa el ser.

Que me interese el ser no es una opción a la que se pueda llegar por el camino de la argumentación.

Que me interese el ser hace parte de mi esencia como ser humano, por ser humano.

Interese:

inter-ese, inter-esse:

entre el ser.

El interés, propio del ser, es lo que le interesa - como es naturalal ser humano, 
quien siempre se pregunta

por el ser de las cosas.

El problema del ser

no es un problema científico

propio solo de académicos.

Nos pertenece

a todos los seres humanos

porque se enraíza

en nuestra naturaleza humana.

El ser

nos interesa...

porque nos interesa lo que las cosas son,

no solo como "cosas", como objetos,

como "útiles",

sino en su más íntimo ser,

en su silencio esencial.

América Latina

no ha olvidado, todavía,

este silencio natural;

se mantiene muy conectada

a sus raíces.

La ciencia moderna y occidental

ha buscado arrebatarnos

este silencio,

ha buscado arrebatarnos

de este silencio,

pero él se ha resistido

y se mantiene

en nuestras tripas.

No hemos olvidado lo que somos.

El olvido del ser

no es universal.

Pertenece solo a una cierta 
tradición cultural

que no es la nuestra, por más que se nos quiera imponer.

¡También el mito de la razón

con su supuesta cientificidad

es una tradición cultural!

¡No es nada objetivo!

El olvido del ser tampoco es objetivo.

¡Verdadea el ser

aún en tiempos de su olvido!

El interés por el ser

se mantiene,

porque nos las habremos con las cosas.

La pregunta por el ser

deviene,

de nuevo,

en búsqueda de comprensión

íntegra.

Sin embargo, necesita

primero liberarse

de las ataduras ónticas

que la han aprisionado.

\section{La negación del ente}

Se hace necesario, entonces, negar

al ente, sin destruirlo.

No se trata de acabar con todo lo que hay.

Se trata de posibilitar otros horizontes

de comprensión,

no (solo) desde la lógica ratiocéntrica

sino desde otras lógicas 
igual de valiosas

y también verdadeantes.

Entre los seres humanos, no existe una sola lógica

ni, ¡menos aún!, ella debe imponerse

sobre todas las demás lógicas

que ofrecen otras culturas

y que han sido menospreciadas

por aquel logos eurocéntrico

que no ha tenido el cuidado

de atender las otras posibilidades

de aproximación a la realidad.

\section{La lógica}

(de la tradición occidental)

con la cual se aproxima al ente

$\mathrm{y}$, desde donde se considera

lo verdadero

(porque resulta "objetivo", "real”, verificable y científico),

es una buena lógica, pero dentro de los límites de lo óntico.

No es la única lógica.

$\mathrm{Ni}$ es la lógica fundamental.

Es una de tantas lógicas.

Como se ve: no se trata

de destruir al ente

ni de destruir su lógica;

se trata, apenas, de negarles

su sentido dogmático

de absolutez

y de universalidad; 
razón por la cual el filósofo argentino

Rodolfo Kusch

ha dado en llamarla

"lógica de la negación".

La lógica óntica

terminó siendo una lógica de la afirmación,

que no hace más que afirmar

al ente

(en su sentido tradicional y metafísico).

Una lógica de la negación

no busca más que negar

la negación

con que se ha negado

toda otra afirmación

distinta a la propia de la lógica

de la afirmación,

para que con los principios

de su misma lógica

se deconstruya y se revele su sentido

—negación de una negación

resulta afirmación-

buscando poder afirmarnos

desde lo existencial.

La realidad íntegra

no se constituye solo de cosas,

de objetividad,

de lo evidenciable de manera científica.

El ente

es insuficiente

para comprender la realidad

toda.

He aquí el primer sentido

de la negación del ente. 
Todo lo óntico sigue estando ahí:

no buscamos su destrucción.

Toda la ciencia sigue estando ahí:

no cuestionamos sus fundamentos teóricos.

Toda la tradición occidental

podrá seguir estando ahí,

¡ella verá!

Pero nos negamos a mantener

ese estado

desde el que se sigue afirmando

una cultura

que quiere seguir imponiéndosenos

acrítica-y-colonialmente,

y desde la cual no se nos permite

cuestionar

sus afirmaciones.

Negar el ente

no quiere decir

negar que todo lo que es

es mero ente

(en el sentido metafísico tradicional

de la filosofía occidental),

$\mathrm{y}$, entonces, tampoco

quiere decir que

solo existe el sentido de ser

(más allá del ente)

y ser

(en sentido ontológico,

como ya lo argumentó Heidegger),

sino que hay

dive r sid a d

en las comprensiones del ser:

ya preónticas,

ya preontológicas, 
ya ontológicas,

ya posontológicas,

ya míticas,

ya místicas,

las hay sencillas y complejas,

las hay lógicas, alógicas, antilógicas,

así como ingenuas, sentientes y sentipensadas...

En América Latina,

ha sido Rodolfo Kusch

quien mejor ha sabido cuestionar

las apuestas

de la metafísica y la ontología

occidentales

que se nos han impuesto.

Pensarnos desde América Latina

posibilita preguntarnos por

la razón de ser

que se ha ido constituyendo

en nuestras formas de comprender

el mundo en que nos encontramos.

Un primer paso metodológico

— si así quiere vérsele-

es desarrollar una lógica de la negación

(no inventada en el medio académico,

así no serviría de mucho,

sino desenraizada de las entrañas mismas

de la cultura popular),

que nos convoque, sin temores,

a sentipensarnos tal cual

somos,

tal cual estamos siendo,

y a mostrarnos desde nuestra más viva

realidad y circunstancia, 
sin buscar huir del hedor que nos nutre, sin avergonzarnos de las estructuras propias que hacen de nuestra esencia seres humanos, pueblos y comunidades, en la mayoría de los casos, populares y populistas, mestizos, mulatos e indígenas, creyentes (en mitos, en religiones o ateístas), con ricas tradiciones culturales, y con sabidurías ancestrales que ni nosotros mismos valoramos por estar enajenados en costumbres extranjeras y advenedizas (sean capitalistas o socialistas, sean científicas o culturalistas).

La negación del ente nos debe llevar —en América Latinaa develar la razón de ser de lo que somos, la semilla del fruto con que nos alimentamos, el sentido de esta(s) cultura(s) en la(s) que hoy día nos encontramos: la mejor posibilidad de nuestra vida.

\section{Seminalidad telúrica}

Hieden los discursos de cientificidad.

Hieden las pruebas de objetividad.

Hieden los silogismos de racionalidad. 
Hieden los avances tecnológicos.

Hiede la higiene, el confort y el comunismo.

Hiede la razón con toda su modernidad.

¡Todo hiede! ¡Hiede todo!, si no se garantizan las mejores posibilidades de vida.

Inclusive hiede el derecho a la vida

si hay derecho al aborto;

hiede el derecho a la vida

si no es más que un pinche derecho,

pues todos los derechos ya hieden

cuando no hay deberes correlativos.

Hiede, también, la democracia

cuando ella se impone armada.

¿Hieden los indígenas

por amar a la Pachamama?,

¿hieden las negritudes

por la nobleza racial que las acompaña?,

¿hieden los mestizos

por la impureza de sus almas?,

¿hedemos los latinoamericanos

por la conexión telúrica

que nos enraíza?

La tierra bajo los pies

clama

el hedor de tanta pantalla, de tanto plomo ya utilizado, de tanto zinc y manganeso desechados, de tanto óxido putrefacto, 
así como de los restos de la industria de plástico y caucho no reutilizados...

pero más clama y más duele

el aire ya no recuperado, arrasado por tanto ente

que lo ha materializado...

¡Hasta dónde hemos llegado!

¡Hasta dónde la industria inconsciente

nos ha colonizado, de forma ingenua!

$¿$ Hay alguien que se detenga

ante aquella flor en la grieta de un muro?

¡Mucho menos habrá quién

se detenga en la grieta de ese muro!

Yo encontré a un ser humano

detenido, contemplando

aquella flor sobre aquel muro

todavía.

¡Es la vida!

No hay vida sin semilla.

La semilla hiede.

No hay vida sin hedor.

¡Todos hedemos!

¡Ni se diga a quienes ya nos lleva la muerte!

Pero, aún, sobre aquel muro

-en su grieta-

florece la flor.

¡Y ello es suficiente! 
¡No todo es mero ente!

¡Hay vida!

¡La vida es!

¡Y el ser de la vida

es todo lo que es!

¡Chistttttttt!

Ser y vida.

(y nada más).

He ahí el sentido de ser

y el sentido del ser.

No hay otro.

Quedarse en silencio

hasta alcanzar esta sabiduría

y hundirse cada vez más

en el corazón

que palpita ese silencio

rítmico,

cuya fuerza se esconde

tras de la misma vida

con que se nutre.

¡Cae la vida en el ser,

como la flor!

No había podido ser de otra manera. 
¡Solo nos falta descubrir América!

¡Solo nos falta acentuar la pasión ontológica

que vive América Latina!

¡Continuemos cantando nuestras penas!

... hasta llegar a la flor que pende de un muro.

¡La vida!

¡Que pende de nuestra existencia!

¡Hay un Amazonas en mi alma!

¡Qué le vamos a hacer!

Y la academia se resiste, ¿qué puedo yo hacer?

No encuentro bordes dónde tantear.

Ya se ha dicho una vez

y no volveré a repetirlo:

el silencio hace parte de la música.

Sin silencio no hay nada.

Todo es silencio, mera melodía.

¡La melodía de la vida!

¡Dancemos

la vida!

Sin temor alguno.

¡La vida que se hace poesía!

¿Cómo podría

no ser? 
Verdaderamente, solo me hace falta

dejar correr una lágrima.

Solo así todo se comprenderá.

Aquella lágrima que me prometiste...

No hay otra.

Solo hay la que es;

no se puede desperdiciar.

Si la vida me ha besado

entonces sabré corresponder,

no seré indigno

de tan noble acto

pasenro.

\section{Desde el suelo del estar}

Encontrándonos con la vida

- viviendo-

estamos.

Pero fijate: siempre

estamos

situados.

Estar

no es algo universal

ni abstracto,

ni racional o lógico...

Estamos.

En un suelo, estamos.

Ente.

Negación.

Vida. 
Estar...

... entidades con identidad,

no meros conceptos

que se pudieran universalizar:

¡bah!

Ente.

Negación.

Vida.

Estar...

... nuestros cuatro puntos cardinales

que orientan

una geocultura

del ser

en cuanto ser.

¡Ea!

Ente.

Negación.

Vida.

Estar...

... como fundamento

que posibilita

desentrañar

la ontología

propuesta por Rodolfo Kusch.

Espiral mandálico, ¡dinámico!

He aquí la geocultura

de una ontología latinoamericana

que ha encontrado su

Sur,

sus raíces,

sus entrañas. 
Ente.

Negación.

Vida.

Estar.

Y desde el suelo del estar

se vuelve a preguntar

por el ser.

¡Mandala ontológico!

En la historia del ser

el filósofo ha encontrado

al ente:

el patio de los objetos.

¿Cómo liberarse de él?

Negando al ente

en cuanto universal,

para posibilitar

de nuevo

la senda del ser;

¿con qué nos encontramos?

Con la vida,

semilla sagrada

que nos orienta

hacia el sur

hediento

al que pertenecemos.

¿Entonces?

Asumiéndolo

sentipensamos

nuestra estancia:

¡estamos!

$Y$ desde este estar tan nuestro

deviene de nuevo 
—aunque no se quisiera-

la pregunta

por el fundamento de lo que somos,

ser.

¡Ser!

¿Ser?

¿Qué es ser?

¿Qué sentido tiene ser?

¿Para qué ser?

Pero, de todas formas,

al final,

cuando se considera haberlo alcanzado todo

y haber apañado entre las manos

una respuesta íntegra

desde la que se sentipiensa

felizmente

la alegría de existir,

ahí, al final,

la palabra inicial

aún no ha sido escrita.

Menos, así, la palabra final.

Tampoco se tiene, aún,

la última palabra.

Sobre el fino filo

de la comprensión

caminamos

sentipensando,

una y otra vez,

nuestro auténtico sentido

de ser, 
$\mathrm{y}$ apenas si vislumbramos

que estamos

siendo.

Estar siendo,

y nada más, cual

mandala infinito

en una chispa de eternidad:

fracto ontológico

que solo nos conduce

a callar.

$\mathrm{Y}$, sin embargo,

como lo hemos podido atalayar,

América Latina

nos señala una posibilidad:

ser desde el estar,

ser desde la vida,

ser desde la negación

del ente.

¿Podríamos no estar?

¿Hiede esta filosofía

que más bien es sabiduría?

¡Y cómo podría ser de otra manera

si apenas estamos

siendo,

y eso nos basta!

Vuelve a callar:

¡mírate el alma!

... es hora

de develar

el sentipensar ontológico

que nos devuelva 
— geoculturalmente-

un sentido de ser,

que a su vez será

sentido del ser

... y nada más.

Estamos.

Estamos siendo.

Nos hace falta

silencio.

Cuando lo logremos

estaremos, ya, armónicamente

constituyendo

la sinfonía de

ser.

Volvemos, entonces, al silencio.

Por lo menos,

al silencio del ente.

Pero no ya al silencio

de las meras palabras

sino al silencio ontológico

donde se comprende

el sentido ontológico

original,

el que quiso hablar en poema

desde Parménides,

y el que quiso acaecer dinámico

desde Heráclito,

para empezar a callar

desde entonces.

No y sí: callar,

sugerir,

esbozar, 
corregir;

intuir,

señalar,

silenciar;

ser,

estar,

confundir;

pensar,

sentipensar,

colorear;

inferir,

proyectar,

comprender;

(...)

Sí... siempre

se vuelve a iniciar:

ser es acontecer

mientras se está.

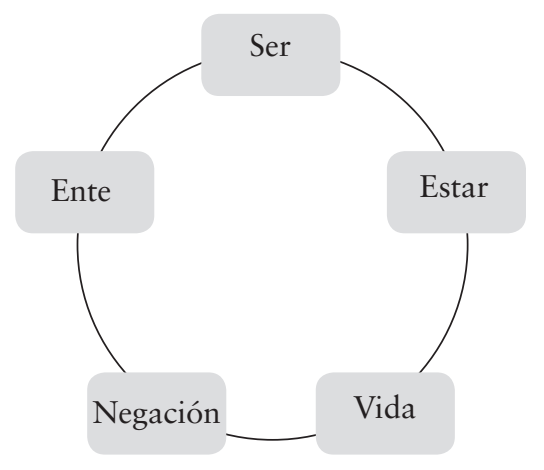

Del ser al estar,

del estar al ser.

Ser. Ente. Negación. Vida. Estar. Ser.

¿Qué se ha podido comprender?

Que el problema del ser 
no es una cuestión abstracta, enredada en conceptos genéricos y supuestas categorías universales.

La esencia del ser está

enraizada

en la geocultura del estar

y nutrida de vida;

dicha vitalidad de ser

deviene

de una negación seminal

que enriquece

y transforma la comprensión

metafísica del ente,

cuya fenomenología

jamás mostrará

la integridad de

lo que es:

lo que se ve, el ente,

no es suficiente

para comprender

lo que es

—originaria y silenciosamente-

el ser. 



\section{Bibliografía}

Anquin, N. (1962). Ente y ser. Perspectivas para una filosofía del ser naciente. Madrid: Gredos

Araújo, M., Maguire, G. y Almeida, C. (eds.) (2007). Metafísica contemporânea. Petrópolis, Brasil: Vozes.

Aristóteles (1994). Metafísica. Libro IV. Madrid: Gredos.

Aristóteles (2010). Del alma. Lisboa: Imprensa Naciona-Casa da Moeda. Recuperado de https://goo.gl/fY87jC

Arroyave, J. (1979). La filosofía en América. Medellín: Etcétera.

Astrada, C. (2005). Martin Heidegger (de la analítica a la dimensión dialéctica). Buenos Aires: Quadrata.

Basave, A. (1982). Tratado de Metafísica. Teoría de la "habencia". México D. F.: Limusa.

Becerra, W. (2008). Ser y estar. Fenomenología y lingüística, un acercamiento a la comprensión de la cultura latinoamericana. Analogías. Revista colombiana de humanidades. Filosofía y multiculturalismo, 72, 141-172.

Bertonio, L. (1879). Vocabulario de la lengua aymara. Cochabamba: Centro de Estudios de la Realidad Económica y Social. Recuperado de https:// goo.gl/HDUJpc 
Beuchot, M. (1997). El núcleo ontológico de la interpretación (la sustancia y el lenguaje). México D. F.: UNIVA, Asociación Filosófica Humanística Mexicana.

Beuchot, M. (2003). El ser y la poesía. El entrecruce del discurso metafísico y el discurso poético. México D. F.: Universidad Iberoamericana.

Beuchot, M. (2013). Hermenéutica analógica y ontología. México D. F.: Cidhem.

Bocco, A. (2002). El concepto de "fagocitación" y sus implicaciones de uso en la crítica literaria latinoamericana. Silabario. Revista de estudios y ensayos geoculturales, (5), 95-103.

Bolaños, E., Cárdenas, J., Cepeda, J., Chicuazuque, V. y Moreno, C. (2016). Estamos siendo. Ontología en poetas latinoamericanos. Bogotá: Ediciones USTA.

Bolda, M. (2003). Metafísica e assombro. Curso de ontologia. São Paulo: Paulo.

Bordas, N. (1989). Kusch y el miedo en América. En E. Azcuy (ed.), Kusch y el pensar desde América (pp. 103-118). Buenos Aires: Fernando García Cambeiro.

Bordas, N. (1997). Ontología a la intemperie. Kusch: ontología desde América. Buenos Aires: Biblos.

Bosio, V. y Haddad, R. (2015). De la música originaria del pueblo Qom a Tonolec. Cuadernos de politicas culturales. Indicadores culturales 2014, 125-136.

Brentano, F. (2007). Sobre los múltiples significados del ente según Aristóteles. Madrid: Encuentro.

Bröcker, W. (2014). Apuntes. En M. Heidegger, Conceptos fundamentales de la filosofía antigua (pp. 343-358). Buenos Aires: Waldhuter.

Cabrera, J. (2014). Crítica de la moral afirmativa. Una reflexión sobre nacimiento, muerte y valor de la vida. Barcelona: Gedisa.

Caturelli, A. (1961). América bifronte. Buenos Aires: Troquel.

Cepeda, J. (2011). Tras del sentido del ser. Aproximaciones a una ontología en perspectiva latinoamericana. Saarbrücken: Editorial Académica Española.

Cepeda, J. (2013). Ontología indígena. Aproximación filosófica a saberes precolombinos que posibilitan una ontología latinoamericana. Aproximaciones ontológicas a lo latinoamericano I, 15-42. 
Cepeda, J. (2014). Cuanto semilla de Kusch. De la sabiduría de América como filosofía latinoamericana [Video]. Iv Jornadas El Pensamiento de Rodolfo Kusch, Caseros. Recuperado de https://goo.gl/BDhrNN

Cepeda, J. (2015). Sentipensar ontológico. Un atisbo latinoamericano de la respuesta a la pregunta por el ser, bajo el horizonte kuscheano del filosofar. Cuadernos de políticas culturales. Indicadores culturales 2014, 195-200.

Cepeda, J. et al. (2015). La hermenéutica textual como herramienta metodológica. Colección Semillas, 1, 13-30.

Cepeda, J. (2017). Sentipensar ontológico. Bogotá: Autores Editores.

Cortés, A. (2007). Heidegger en la de-colonización del pensar en Latinoamérica. Cuadernos de filosofía latinoamericana, 28(97), 43-50.

Cullen, C. (2015). La resistencia geocultural a la ilusoria y peligrosa levedad del pensamiento único. Cuadernos de políticas culturales. Indicadores culturales 2014, 68-72.

Ellacuría, I. (1974). Metafísica. Inédito. Universidad José Simeón Cañas, San Salvador.

Fiori, E. (1987). Metafísica e história. Textos escolbidos. Volume I. Porto Alegre: L\&PM.

Flores, G. (2014). Resentimiento metafísico e inversión de los valores. Lima: Iipcial.

Fornet-Betancourt, R. (2001). Transformación intercultural de la filosofía. Ejercicios teóricos y prácticos de filosofía intercultural desde Latinoamérica en el contexto de la globalización. Bilbao: Desclée de Brower.

García, J. (1963). Metafísica natural estabilizada y problemática metafísica espontánea. México D. F.: Fondo de Cultura Económica.

Giannini, H. (2007). La metafísica eres tú. Una reflexión ética sobre la intersubjetividad. Santiago de Chile: Catalonia.

Guamán, F. (2005). Nueva crónica y buen gobierno. México D. F.: Fondo de Cultura Económica.

Guzmán, I. (1947). Para una metafísica social. Ensayo de investigación filosófica sobre la esencia y existencia de la sociedad. México D. F.: Jus.

Haber, A. (1989). Reflexiones sobre el estar en la filosofía de Rodolfo Kusch. En E. Azcuy (ed.), Kusch y el pensar desde América (pp. 45-51). Buenos Aires: Fernando García Cambeiro. 
Heidegger, M. (1963). Sein und Zeit. Tübingen: Max Niemeyer Verlag.

Heidegger, M. (1968). Hoelderlin y la esencia de la poesía. Mérida: Universidad de los Andes.

Heidegger, M. (1979). ¿Qué es metafísica? Buenos Aires: Siglo xx.

Heidegger, M. (1996). Kant y el problema de la metafísica. México D. F.: Fondo de Cultura Económica.

Heidegger, M. (2000a). Los problemas fundamentales de la fenomenología. Madrid: Trotta.

Heidegger, M. (2000b). Nietzsche, I. Barcelona: Destino.

Heidegger, M. (2000c). Nietzsche, II. Barcelona: Destino.

Heidegger, M. (2001a). Conferencias y artículos. Barcelona: Ediciones del Serbal.

Heidegger, M. (2001b). El origen de la obra de arte. En M. Heidegger, Caminos de bosque (pp. 11-62). Madrid: Alianza.

Heidegger, M. (2001c). La sentencia de Anaximandro. En M. Heidegger, Caminos de bosque (pp. 239-277). Madrid: Alianza.

Heidegger, M. (2002). Interpretaciones fenomenológicas sobre Aristóteles. Indicación de la situación hermenéutica. (Informe Natorp). Madrid: Trotta.

Heidegger, M. (2003). Introducción a la metafísica. Barcelona: Gedisa.

Heidegger, M. (2004). Lógica. La pregunta por la verdad. Madrid: Alianza.

Heidegger, M. (2006a). Introducción a la investigación. Madrid: Síntesis.

Heidegger, M. (2006b). La fenomenología del espíritu de Hegel. Madrid: Alianza.

Heidegger, M. (2006c). Aportes a la filosofía. Acerca del evento. Buenos Aires: Biblos.

Heidegger, M. (2006d). Meditación. Buenos Aires: Biblos.

Heidegger, M. (2007a). Carta sobre el Humanismo. En M. Heidegger, Hitos (pp. 259-297). Madrid: Alianza.

Heidegger, M. (2007b). En torno a la cuestión del ser. En M. Heidegger, Hitos (pp. 313-344). Madrid: Alianza.

Heidegger, M. (2007c). De la esencia de la verdad. Barcelona: Herder.

Heidegger, M. (2007d). La tesis de Kant sobre el ser. En M. Heidegger, Hitos (pp. 361-388). Madrid: Alianza. 
Heidegger, M. (2007e). Hegel y los griegos. En M. Heidegger, Hitos (pp. 345 359). Madrid: Alianza.

Heidegger, M. (2007f). Sobre el comienzo. Buenos Aires: Biblos.

Heidegger, M. (2008a). Ontología. Hermenéutica de la facticidad. Madrid: Alianza.

Heidegger, M. (2008b). Preguntas fundamentales de la filosofía. Granada: Comares.

Heidegger, M. (2010). Los himnos de Hölderlin "Germania” y "El Rin”. Buenos Aires: Biblos.

Heidegger, M. (2011). La historia del ser. Buenos Aires: El Hilo de Ariadna.

Heidegger, M. (2014a). Conceptos fundamentales de la filosofía antigua. Buenos Aires: Waldhuter.

Heidegger, M. (2014b). Problemas fundamentales de la fenomenología (1919/1920). Madrid: Alianza.

Herrera, D. (2007). Heidegger, ¿filósofo del misterio? [Separata]. Bogotá: Universidad Pedagógica Nacional.

Higuera, É. (2014). Negación del ser para el reconocimiento del otro. Sophia. Ontología de la educación, 17, 139-159.

Holguín, D. (1608). Vocabulario de la lengua quechua. Lima: Imprenta de Francisco del Canto.

Hoyos, J. (1976). Kant y el problema de la metafísica [Separata]. Ideas y valores, 48-49, 67-129.

Ibérico, M. (1946). El sentimiento de la vida cósmica. Buenos Aires: Losada.

Kant, I. (1988). Crítica de la razón pura. Madrid: Alfaguara.

Kusch, R. (2000a). De la mala vida porteña. En R. Kusch, Obras completas. Tomo I (pp. 323-466). Rosario: Ross.

Kusch, R. (2000b). Indios, porteños y dioses. En R. Kusch, Obras completas. Tomo I (pp. 135-322). Rosario: Ross.

Kusch, R. (2000c). La seducción de la barbarie. En R. Kusch, Obras completas. Tomo I (pp. 17-134). Rosario: Ross.

Kusch, R. (2003a). América profunda. En R. Kusch, Obras completas. Tomo II (pp. 1-254). Rosario: Ross.

Kusch, R. (2003b). El pensamiento indígena y popular en América. En R. Kusch, Obras completas. Tomo II (pp. 255-546). Rosario: Ross. 
Kusch, R. (2003c). La negación en el pensamiento popular. En R. Kusch, Obras completas. Tomo II (pp. 567-698). Rosario: Ross.

Kusch, R. (2007a). Esbozo de una antropología filosófica americana. En R. Kusch, Obras completas. Tomo III (pp. 241-434). Rosario: Ross

Kusch, R. (2007b). Geocultura del hombre americano. En R. Kusch, Obras completas. Tomo III (pp. 5-240). Rosario: Ross.

Lértora, C. (2001). Reflexión final: Kusch y la crisis de la metafísica. En C. Lértora et al., Reflexiones actuales sobre el pensamiento de Rodolfo Kusch (pp. 27-29). San Salvador de Jujuy: Universidad Nacional de Jujuy.

Lima, H. (1968). Ontología e Historia. São Paulo: Duas Cidades.

Lisboa, A. (coord.) (2009). A poesia metafísica no Brasil. Percursos e modulações. Porto Alegre: Faculdade Porto-Alegrense.

Marquínez, G. (1993). Metafísica desde Latinoamérica. Bogotá: Ediciones USTA.

Maturo, G. (2004). De la poética metafísica de Leopoldo Marechal a una hermenéutica y fenomenología de lo imaginario. En G. Maturo, La razón ardiente. Aportes a una teoría literaria latinoamericana (pp. 57-69). Buenos Aires: Biblos.

Miró, F. (1951). Ensayos I. (Ontología). Lima: Imprenta Santa María.

Mora, Z. (2001). Filosofía mapuche. Palabras arcaicas para despertar el ser. Santiago de Chile: Cerro Manquehue.

Mörchen, H. (2014). Apuntes. En M. Heidegger, Conceptos fundamentales de la filosofía antigua (pp. 241-342). Buenos Aires: Waldhuter.

Mujica, H. (2010). La palabra inicial. La mitología del poeta en la obra de Heidegger. Buenos Aires: Biblos.

Nishida, K. (2006). Pensar desde la nada. Ensayos de filosofía oriental. Salamanca: Sígueme.

Oñate, T., Cubo, Ó., Zubía, P. y Núñez, A. (2012). El segundo Heidegger: Ecología. Arte. Teología. En el 50 aniversario de Tiempo y ser. Madrid: Dykinson.

Pachacuti, J. (1950). Relación de antigüedades deste reyno del Pirú. En F. Santillán, B. Valera y J. Pachacuti, Tres relaciones de antigüedades peruanas (pp. 205-281). Asunción del Paraguay: Guarania.

Pagano, C. (1999). Un modelo de filosofía intercultural: Rodolfo Kusch (19221979). Aproximación a la obra del pensador argentino. Aachen: Mainz. 
Pérez, A. (2006). Imaginación literaria y pensamiento propio. Buenos Aires: Corregidor.

Pérez, D. (2013). El estar siendo del ardid litúrgico. El cuerpo en tanto mediación con la trascendencia (hedor del puro vivir). En J. Tasat y J. Pérez (coords.), El hedor de América. Reflexiones interdisciplinarias a 50 años de la América profunda de Rodolfo Kusch (pp. 111-115). Buenos Aires: Centro Cultural de la Cooperación y Universidad Nacional de Tres de Febrero.

Picotti, D. (2010). Heidegger. Una introducción. Buenos Aires: Quadrata.

Rivera, J. (2007). En torno al ser. Ensayos filosóficos. Santiago de Chile: Brick.

Rodríguez, R. (2002). Métodos del pensamiento ontológico. Madrid: Síntesis.

Rosales, A. (1993). La diferencia ontológica en la obra de Heidegger. Texto $y$ contexto, 21, 26-41.

Sada, G. (1996). Los caminos americanos de la filosofía en Rodolfo Kusch. Buenos Aires: Fernando García Cambeiro.

Scannone, J. (1989). Estar-ser-acontecer. El horizonte tridimensional del pensar filosófico latinoamericano. En A. Azcuy (coord.), Kusch y el pensar desde América (pp. 73-76). Buenos Aires: Fernando García Cambeiro.

SEMEyon (2013). A lo profundo de Kusch. Tras una ontología latinoamericana. Bogotá: Nueva América y Tlamatinime.

Stein, E. (2001). Comprensão e finitude. Estrutura e movimento da interrogação heideggeriana. Ijuí: Unijuí.

Vasconcelos, J. (1929). Tratado de metafísica. México D. F.: México Joven.

Vázquez, A. (1964). Qué es la ontología. Buenos Aires: Columba.

Volpi, F. (2012). Heidegger y Aristóteles. Buenos Aires: Fondo de Cultura Económica.

Wagner, A. (1939). La ontología fundamental de Heidegger. Su motivo y significación. Buenos Aires: Losada.

Wajnerman, C. (2013). ¿Algo huele mal? Vías hacia el bien-estar americano entre olor, vínculos y símbolos. En J. Tasat y J. Pérez (coords.), El hedor de América. Reflexiones interdisciplinarias a 50 años de la América profunda de Rodolfo Kusch. Buenos Aires: Centro Cultural de la Cooperación y Universidad Nacional de Tres de Febrero. 




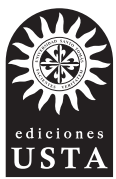

Esta obra se editó en Ediciones USTA.

Se usó papel propalcote de 280 gramos para la carátula y papel bond beige de 75 gramos para páginas internas.

Tipografía de la familia Sabón.

2019 


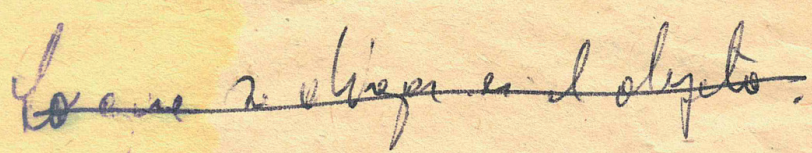

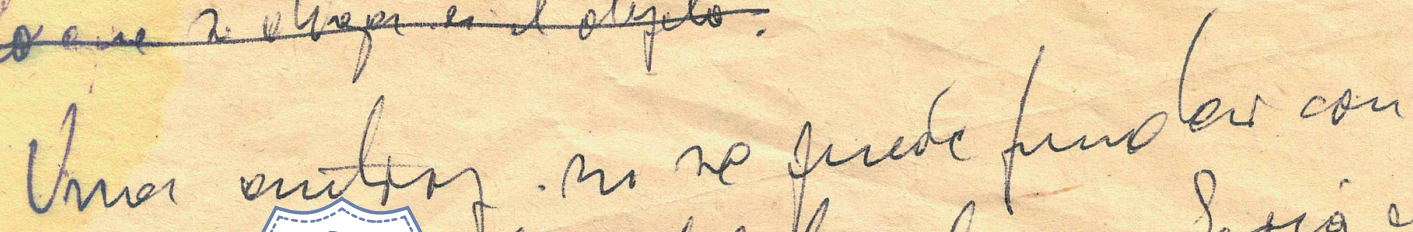

En esta obra, el problema ontológico se aborda bajo una visión renovada por Martín Heidegger, quien busca destruir la metafísica del ente, proponiendo una revitalización dinámica que este filósofo trae hasta los límites de la poesía. Pero el primer poeta del ser fue Parménides, por lo que esta investigación presenta, en seguida, el ejercicio de con-versar con aquel maestro de la ontología griega. Ganado, así, el horizonte disciplinar, se inicia el camino de comprensión de lo ontológico en la obra filosófica de Rodolfo Kusch, con el fin de proponer otro sentido de ser, ahora desde el horizonte intercultural latinoamericano, que se configura mandálicamente según las estructuras del pensamiento ancestral. Juan Cepeda H. radicaliza esta propuesta en versos que le apuestan a la esencia del ser enraizada en la geocultura del estar, devenida negativamente, constituyéndose vida que solo se comprenderá en su totalidad, después, en el sentipensar ontológico.

4 dellt caster de now

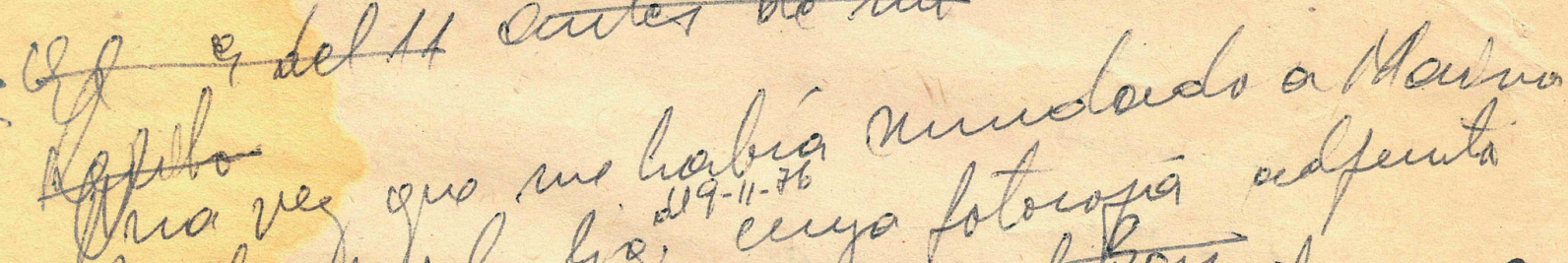

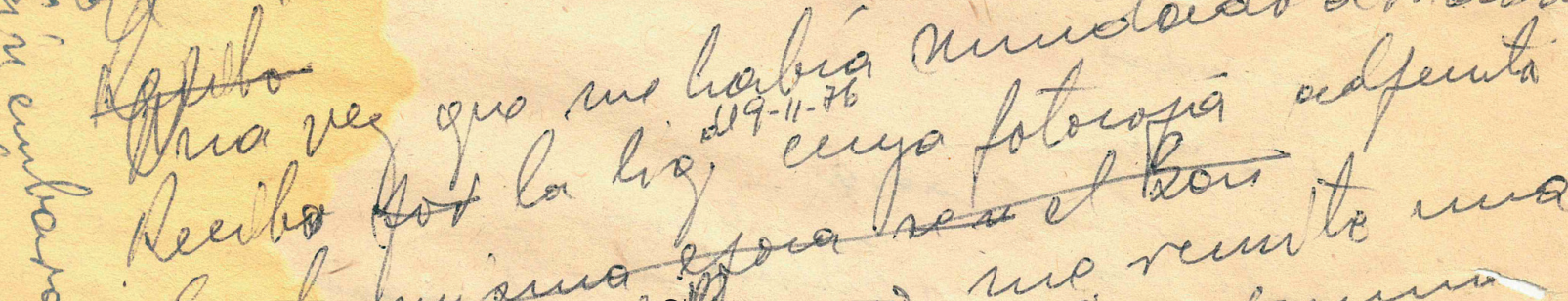

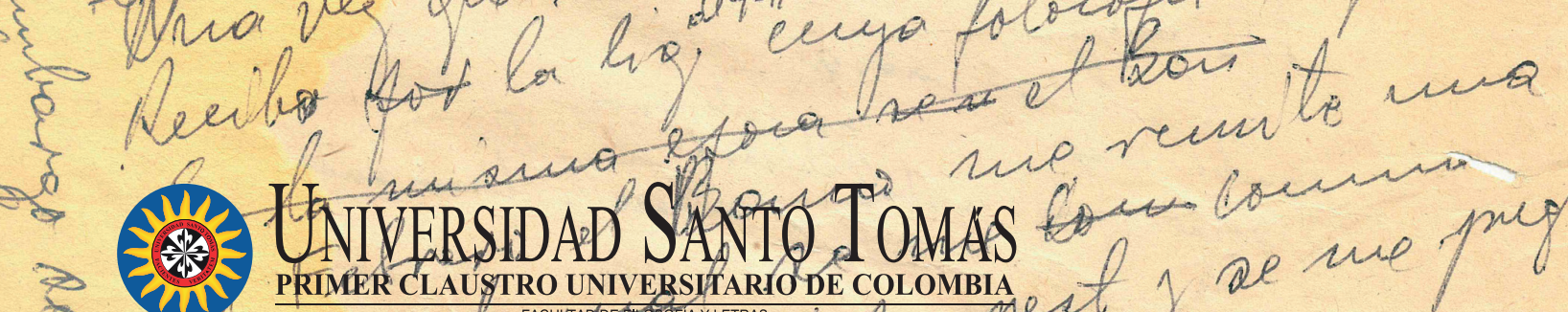

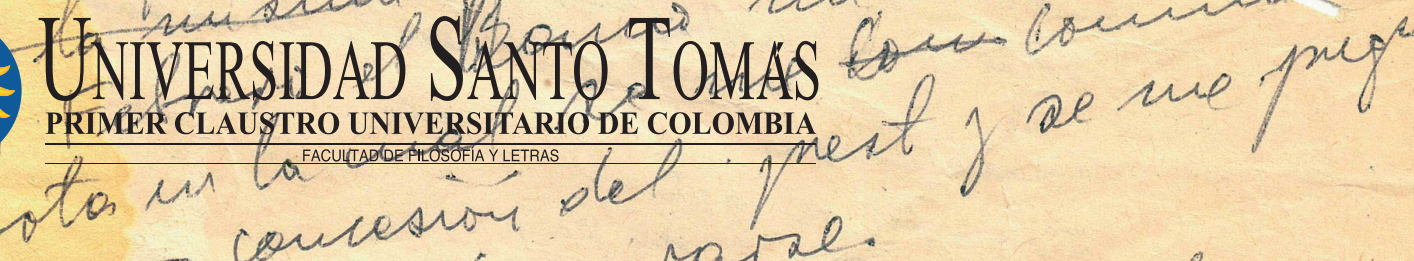
concesiriral. 